удК 343.1

Э. Р. Исламова

Академия Генеральной прокуратуры Российской Федерации, г. Санкт-Петербург, Российская Федерация

\title{
К ВОПРОСУ О СООТНОШЕНИИ ПРОЦЕССУАЛЬНЫХ ПОЛНОМОЧИЙ ПРОКУРОРА И РУКОВОДИТЕЛЯ СЛЕДСТВЕННОГО ОРГАНА
}

\begin{abstract}
АНнотАция. Положения Уголовно-процессуального кодекса Российской Федерации, посвященные участникам уголовного судопроизводства со стороны обвинения, в 2007 и 2010 г. претерпели существенные изменения: появился новый участник руководитель следственного органа, которому были переданы многие полномочия, ранее принадлежавшие прокурору. Возникающие между прокурором и руководителем следственного органа процессуальные отношения требуют изучения и осмысления. $К$ настоящему времени сформировалась практика применения измененных норм уголовно-процессуального законодательства, обозначились проблемы, требующие урегулирования. В этой связи в статье проведен анализ законодательства и правоприменительной практики, а также представлены результаты исследования мнения прокурорских работников по проблеме соотношения процессуальных полномочий прокурора и руководителя следственного органа. Отмечены существенные недостатки правовой регламентации полномочий прокурора. Сформулированы предложения по изменению Уголовно-процессуального кодекса Российской Федерации, связанные с наделением прокурора дополнительными полномочиями и направленные на обеспечение законности уголовно-процессуальной деятельности. кЛючЕВЫЕ слОВА. Прокурор; руководитель следственного органа; процессуальные полномочия; требование; возбуждение уголовного дела; предварительное расследование; процессуальные отношения.
\end{abstract}

ИНФОРМАЦИЯ О СТАТЬЕ. Дата поступления 16 февраля 2016 г.; дата принятия к печати 26 февраля 2016 г.; дата онлайн-размещения 23 марта 2016 г.

E. R. Islamova

Academy of General Prosecutor's Office of the Russian Federation, Saint-Petersburg, Russian Federation

\section{ON ISSUE OF CORRELATION OF PROSECUTOR'S PROCEDURAL POWERS AND HEAD OF INVESTIGATIVE BODY}

\begin{abstract}
Provisions of the Criminal Procedure Code of the Russian Federation, devoted to participants of criminal procedure on the part of prosecution, underwent significant changes in 2007 and 2010: a new participant, Head of the investigative body, was introduced to whom many powers were deputed that previously had belonged to the Prosecutor. Procedure relations arising between the prosecutor and the head of investigative body demand studying and understanding. By now, the practice of applying the changed standards of criminal procedure legislation has taken shape, and the problems that require regulation have been identified. In that context, the article carries out an analysis of the legislation and law enforcement practice, as well as presents the result of studying the opinion survey of procuracy officers on the issue of correlating procedural powers of the prosecutor and the head of investigative body. It notes considerable drawbacks of legal regulation of the prosecutor's powers. It states proposals on changes in Criminal Procedure Code of the Russian Federation connected with vesting the prosecutor with additional powers and directed at providing the criminal procedural activities with legitimacy.
\end{abstract}

KEYWORDS. Prosecutor; Head of investigative body; procedural powers; demand; initiation of a criminal case; preliminary investigation; procedural relationships.

ARTICLE INFO. Received February 16, 2015; accepted February 26, 2015; available online March 23, 2016.

\section{Baikal Research Journal}


Внесение в Уголовно-процессуальный кодекс Российской Федерации (УПК РФ) изменений на основании Федерального закона от 5 июня 2007 г. № $87-\Phi 3^{1}$ повлекло перераспределение процессуальных полномочий между прокурором и новым участником уголовного судопроизводства со стороны обвинения - руководителем следственного органа. Так, руководитель следственного органа был наделен ранее принадлежавшими прокурору полномочиями, связанными с процессуальным руководством (дача следователям указаний, касающихся направления расследования, производства следственных действий, привлечения лица в качестве обвиняемого, избрания меры пресечения, квалификации преступления и об объеме обвинения; согласование ходатайств следователей об избрании, продлении, отмене или изменении меры пресечения, а также иных процессуальных действий, которые производятся на основании судебных решений; разрешение отводов, заявляемых следователям, а также их самоотводов; решение вопроса об отстранении следователей от расследования при нарушении ими требований УПК РФ; продление срока предварительного расследования). Кроме того, руководитель следственного органа, осуществляя процессуальный контроль, наделен полномочиями по отмене незаконных и необоснованных постановлений следователя, руководителя следственного органа, дознавателя (в том числе другого органа предварительного расследования), а также возвращению уголовных дел следователю со своими указаниями о производстве дополнительного расследования.

Одновременно прокурор был лишен прав на возбуждение уголовных дел, поручение их расследования, а также принятие к своему производству, осуществление предварительного расследования и дачу письменных указаний, касающихся направления расследования, производства следственных и иных процессуальных действий, согласование ходатайств следователя об избрании, отмене или изменении меры пресечения, о производстве иных процессуальных действий, которые производятся на основании судебных решений, разрешение отводов следователю, а также их самоотводов, отстранение следователей от расследования, продление срока предварительного расследования.

Такие изменения не могли не вызвать проблем правоприменения и дискуссий ученых о функциях, полномочиях прокурора и руководителя следственного органа, а также их процессуальных отношениях. Изучению этих вопросов посвящено большое количество научных исследований, в том числе диссертационного уровня [1-3; 4, с. $133-136 ; 5 ; 6$, с. $106 ; 7$, с. $109-123 ; 8]$.

Процессуалистами совершенно обоснованно отмечается, что в связи с указанными изменениями уголовно-процессуального законодательства сложился «конфликт полномочий" руководителя следственного органа и прокурора $[9$, с. $12 ; 10 ; 11]$, возникла проблема оптимального разделения труда между должностными лицами государственных органов, выступающих на одной процессуальной стороне и оптимизации процедуры досудебного производства [8, с. 27]. В. Ф. Крюков справедливо указывает, что в современных условиях для реализации назначения уголовного судопроизводства на его досудебных стадиях важное значение имеют правильное уяснение и ответственное, основанное на уголовно-процессуальном законодательстве выстраивание процессуальных отношений надзирающего прокурора и руководителя следственного органа [1;2].

В целях изучения указанных проблем автором обобщены результаты проведенного в 2015 г. исследования мнений 118 прокурорских работников, занимающих

\footnotetext{
${ }^{1} \mathrm{O}$ внесении изменений в Уголовно-процессуальный кодекс Российской Федерации и Федеральный закон «О прокуратуре Российской Федерации» : федер. закон от от 5 июня 2007 г. № 87-ФЗ // Собрание законодательства Российской Федерации. 2007. № 24. Ст. 2830.
}

\section{Baikal Research Journal}


должности прокуроров, а также их заместителей и помощников, осуществляющих свою деятельность в сфере уголовного судопроизводства.

В юридической литературе высказывается спорное суждение о том, что в настоящее время отсутствует необходимость двойного контроля работы следователя и содержания аппарата работников, осуществляющих надзор за результатами его работы [12, с. 20-22], тем самым вновь ставится под сомнение необходимость существования полномочий прокурора по осуществлению надзора в уголовном процессе.

Вместе с тем, УПК РФ закрепил за прокурором надзорные полномочия, установив в ч. 1 ст. 37 , что прокурор в пределах предоставленной ему компетенции осуществляет две функции: уголовное преследование и надзор за процессуальной деятельностью органов предварительного расследования. При этом, несмотря на то, что функция надзора указана в ст. 37 УПК РФ после уголовного преследования, именно прокурор обязан обеспечить законность уголовного преследования. Прокурор является участником уголовного судопроизводства, реализующим функцию прокурорского надзора, в связи с чем у него иное назначение по сравнению с другими участниками уголовного судопроизводства со стороны обвинения. Прокурор, осуществляющий надзор за процессуальной деятельностью органов предварительного расследования, располагается на более высоком уровне в системе органов, осуществляющих уголовное преследование. Б. Я. Гавриловым обоснованно отмечена особенность прокурорского надзора в уголовном судопроизводстве, заключающаяся в том, что он, являясь органической частью уголовного процесса, все же стоит над процессуальной деятельностью иных участников уголовного судопроизводства со стороны обвинения [13].

С учетом этого представляется правильным мнение авторов, полагающих, что, определяя соотношение функций надзора и уголовного преследования в деятельности прокурора, следует исходить из того, что уголовно-процессуальная деятельность многофункциональна, и функции осуществляющих ее субъектов иерархически соподчинены: дополнительные способствуют осуществлению основной функции, и подчиняются ей; основная функция участника отражает сущность и главную направленность его деятельности $[14$, с. $39-40 ; 15$, с. 7]. Для реализации основной функции законодателем в уголовный процесс включены самостоятельные субъекты - следователь, руководитель следственного органа, орган дознания, дознаватель, прокурор, суд, защитник, совместными действиями осуществляющие уголовное судопроизводство. Основной задачей прокурора в досудебных стадиях уголовного судопроизводства является надзор за соблюдением прав и свобод человека и гражданина, а также за исполнением законов органами дознания и предварительного следствия. Приоритетный характер функции надзора в досудебных стадиях уголовного судопроизводства подтверждается тем, что прокурор указан в УПК РФ как единственный субъект данной функции, уголовное преследование - для него важная, но дополнительная функция.

Однако в настоящее время возможности прокурора по реализации функции надзора в досудебных стадиях уголовного судопроизводства ограничены. Так, например, 78 \% опрошенных прокурорских работников полагают, что процессуальные полномочия прокурора в стадии возбуждения уголовного дела недостаточны для осуществления эффективного прокурорского надзора.

Прокурор не наделен полномочием по отмене любых незаконных и необоснованных постановлений следователя без использования сложного порядка направления прошений об их отмене руководителю следственного органа. Исключение составляют лишь постановления о возбуждении и отказе в возбуждении уголовного дела.

Согласно ч. 4 ст. 39 УПК РФ, установив факт принятия следователем незаконного и необоснованного постановления либо иного нарушения федерального зако-

\section{Baikal Research Journal}

электронный научный журнал Байкальского государственного университета 
нодательства, допущенного в ходе досудебного производства, прокурор должен направить руководителю следственного органа соответствующее требование, которое рассматривается в срок не позднее пяти суток. При этом в уголовно-процессуальном законе отсутствует положение об обязательности исполнения требования прокурора, в связи с чем руководитель следственного органа может вынести мотивированное постановление о несогласии с требованиями прокурора. В такой ситуации прокурор должен использовать предоставленное ему полномочие по «обжалованию» принятого процессуального решения, предусмотренное ч. 6 ст. 37 УПК РФ. Если же руководитель следственного органа либо следователь не согласится с требованиями прокурора, то прокурор вправе обратиться с требованием об устранении указанных нарушений к руководителю вышестоящего следственного органа. Однако руководитель вышестоящего следственного органа также может не выразить согласия с требованиями прокурора, который в этом случае вправе обратиться к Председателю Следственного комитета Российской Федерации либо к руководителю следственного органа федерального органа исполнительной власти. Если и указанные должностные лица не выскажут свое мнение об обоснованности требований прокурора, то окончательное решение принимает Генеральный прокурор Российской Федерации. Такой порядок не способствует оперативному устранению процессуальных нарушений и своевременному восстановлению прав граждан, вовлеченных в уголовное судопроизводство.

Отдельными авторами в качестве выхода из сложившейся ситуации предлагается закрепление права прокурора на обращение в случае отклонения его требований об устранении нарушений закона руководителем следственного органа в суд, который сможет разрешить возникший конфликт в течение пяти суток [7, с. 122-123]. Однако введение такого порядка лишь закрепит статус прокурора как просителя, заявителя, «жалобщика» [16, с. 52].

В этой связи следует согласиться с учеными, предлагающими установить в уголовно-процессуальном законе порядок неукоснительного исполнения требований прокурора, а также возможность обжалования следователем с согласия руководителя следственного органа таких требований вышестоящему прокурору [17, с. 54]. Мнение о том, что требования прокурора должны быть обязательными для исполнения и при несогласии с требованиями прокурора следователь и руководитель следственного органа вправе обжаловать их вышестоящему прокурору либо в суд, при этом такое обжалование не должно приостанавливать требование прокурора, поддерживают 93,4\% опрошенных респондентов.

Исходя из буквального толкования положений п. 3 ч. 2 и ч. 6 ст. 37 УПК РФ, прокурор уполномочен потребовать устранения нарушений федерального законодательства, допущенных только в ходе дознания или предварительного следствия, тогда как на основании ч. 4 ст. 39 УПК РФ прокурор уполномочен на внесение требований об устранении иных нарушений федерального законодательства, допущенных в ходе досудебного производства, т. е. и в стадии возбуждения уголовного дела. Представляется, что все полномочия прокурора, в том числе по требованию от органов предварительного расследования устранения нарушений федерального законодательства, допущенных в стадии возбуждения уголовного дела, должны быть четко закреплены в ст. 37 УПК РФ, посвященной именно этому участнику уголовного судопроизводства, с таким мнением согласилось 96,3 \% опрошенных прокурорских работников.

В настоящее время в соответствии с ч. 2.1 ст. 37 УПК РФ прокурору по его мотивированному письменному запросу предоставляется возможность ознакомиться лишь с материалами находящегося в производстве уголовного дела, в связи с чем 89,5 \% опрошенных прокурорских работников высказали мнение о необходимости

\section{Baikal Research Journal}

электронный научный журнал Байкальского государственного университета 
закрепления в УПК РФ обязанности органа дознания, дознавателя, руководителя следственного органа, следователя по незамедлительному представлению прокурору по его требованию не только уголовного дела, но материалов и проверки сообщения о преступлении.

Кроме того, несмотря на то, что имеются многочисленные предложения как практических работников, так и ученых вернуть прокурору право возбуждения уголовных дел [14, с. $102 ; 16$, с. $49-53 ; 18$, с. $12-15 ; 19$, с. $84 ; 20-22]$, у прокурора такое эффективное полномочие по устранению выявленных нарушений уголовного законодательства отсутствует. В связи с этим 90,7 \% респондентов полагают, что необходимо вернуть прокурору полномочие по возбуждению уголовных дел, 5 \% считают, что имеется необходимость наделения прокурора таким полномочием только по результатам проверок прокурором законности постановлений об отказе в возбуждении уголовного дела и 4,3 \% опрошенных считают, что необходимость в таком полномочии отсутствует. Представляется, что прокурор должен иметь право возбуждать уголовные дела как в целях устранения нарушений, выявленных в ходе проверок исполнения закона при вынесении решений об отказе в их возбуждении, так и при выявлении оснований для возбуждения уголовных дел по результатам проверок соблюдения Конституции Российской Федерации и исполнения законов.

Функции руководителя следственного органа в уголовно-процессуальном законе не указаны, что вызывает отсутствие единого мнения среди ученых. Так, например, Т. Ю. Попова указывает, что основной, но не единственной функцией, осуществляемой руководителем следственного органа на предварительном следствии, является процессуальное руководство, дополнительной - процессуальный контроль. К факультативным функциям относятся направления деятельности, являющиеся для него эпизодическими и не влияющими на объем реализации его задач: надзорная функция, функция организации работы следственного подразделения и функция уголовного преследования [10, с. 8]. При этом не учитывается, что согласно положениям УПК РФ надзорную функцию осуществляет лишь прокурор. В. А. Шабунин полагает, что деятельность руководителя следственного органа носит бифункциональный характер, поскольку он осуществляет две взаимосвязанные и взаимообусловленные функции - расследование обстоятельств совершенного преступления и ведомственного процессуального контроля (руководства таким расследованием) [7, с. 12]. Н. А. Моругина выделяет в качестве основной функцию процессуального руководства деятельностью следователя (координацию деятельности следователя, направление расследования), к дополнительным относит контроль за процессуальной деятельностью следователя (проверку и оценку доказательств, собранных следователем; выявление и устранение допущенных нарушений) и уголовное преследование; обвинения [23, с. 8].

Анализ норм уголовно-процессуального законодательства позволяет сделать вывод об осуществлении руководителем следственного органа функции уголовного преследования и ведомственного процессуального контроля. В настоящее время продолжает оставаться актуальной проблема обеспечения такого положения, при котором субъекты, осуществляющие контрольную и надзорную функции, дополняли друг друга, а не подменяли [24, с. 20].

Эффективное устранение допущенных органами предварительного расследования ошибок, восстановление нарушенных прав гражданина возможно при условии существования системы многовариантных средств и способов защиты прав и законных интересов личности, в которой один из способов защиты контролирует другой. Представляется, что в досудебных стадиях уголовного процесса прокурорский надзор, ведомственный и судебный контроль должны обеспечивать такую альтернативную систему средств обеспечения законности и обоснованности решений и действий

\section{Baikal Research Journal}

электронный научный журнал Байкальского государственного университета 
(бездействия). В этой системе отсутствуют взаимозамена и дублирование. Надзор и контроль дополняют друг друга, используя принадлежащие им формы и методы, поэтому является правильным утверждение, что возможность граждан обращаться с жалобами в суд стимулирует повышение качества как работы органов предварительного расследования, так и эффективность прокурорского надзора [25, с. 253].

Прокурор, обеспечивая законность и обоснованность осуществления уголовного преследования, а также защиту прав и законных интересов участников уголовного судопроизводства, является гарантом исполнения уголовно-процессуального законодательства на досудебных стадиях уголовного процесса, а руководитель следственного органа - организатор процессуальной деятельности по расследованию преступлений органами предварительного следствия $[1 ; 2]$.

В связи с этим следует сохранить как ведомственный процессуальный контроль руководителя следственного органа, достоинством которого является оперативность и возможность непрерывного наблюдения за исполнением установленного законом порядка осуществления уголовно-процессуальной деятельности ввиду непосредственной приближенности к объекту контрольной деятельности, так и объективный, независимый от ведомственных влияний прокурорский надзор. При этом у надзирающего прокурора процессуальных полномочий должно быть не меньше, чем у осуществляющего процессуальный контроль руководителя следственного органа.

С учетом этого, представляется необходимым в процессуальной деятельности прокурора и руководителя следственного органа обеспечить совместную реализацию ими положений ст. 6 УПК РФ, устанавливающей назначение уголовного судопроизводства (защиту прав и законных интересов лиц и организаций, потерпевших от преступлений, а также защиту личности от незаконного и необоснованного обвинения, осуждения, ограничения ее прав и свобод), а не противопоставление и конкуренцию.

\section{Список использованной литературы}

1. Крюков В. Ф. Уголовное преследование в досудебном производстве: уголовно-процессуальные и надзорные аспекты деятельности прокурора : монография / В. Ф. Крюков. - М. : Норма, 2010. - $480 \mathrm{c}$.

2. Крюков В. Ф. Правовой статус прокурора в уголовном преследовании: досудебное и судебное производство : автореф. дис. ... д-ра юрид. наук : 12.00 .09 / В. Ф. Крюков. - М., 2012. $-51 \mathrm{c}$.

3. Терёхин А. А. Акты прокурорского реагирования в российском уголовном судопроизводстве : автореф. дис. ... канд. юрид. наук : 12.00 .09 / А. А. Терёхин. - Челябинск, 2013. - 19 с.

4. Новиков Е. А. Руководитель следственного органа в российском уголовном судопроизводстве: процессуальные и организационные аспекты : дис. ... канд. юрид. наук : 12.00.09 / Е. А. Новиков. - М., 2009. - 271 с.

5. Маслов И. В. Прокурорский надзор и ведомственный контроль в уголовном процессе России: функции, анализ системных связей / И. В. Маслов // Российский следователь. 2013. 一 № 19. - С. 27-32.

6. Моругина Н. А. Руководитель следственного органа как участник уголовного судопроизводства со стороны обвинения : дис. ... канд. юрид. наук : 12.00 .09 / Н. А. Моругина. - М., 2010. $-221 \mathrm{c}$.

7. Шабунин В. А. Руководитель следственного органа: нормативное регулирование и практика осуществления процессуальных функций и полномочий : автореф. дис. ... канд. юрид. наук : 12.00.09 / В. А. Шабунин. - Саратов, 2013. - 42 с.

8. Иванова Е. В. Руководитель следственного органа как субъект уголовного судопроизводства : автореф. дис. ... канд. юрид. наук : 12.00 .09 / Е. В. Иванова. - Екатеринбург, 2014. $-28 \mathrm{c}$.

9. Минаева С. А. Процессуальная деятельность руководителя следственного органа по обеспечению законности в досудебном производстве : автореф. дис. ... канд. юрид. наук : 12.00 .09 / С. А. Минаева. - М., 2014. - 26 с.

\section{Baikal Research Journal}

электронный научный журнал Байкальского государственного университета 
10. Попова Т. Ю. Уголовно-процессуальный статус руководителя следственного органа : автореф. дис. ... канд. юрид. наук : 12.00.09 / Т. Ю. Попова. - Челябинск, 2012. - 30 с.

11. Законность в досудебных стадиях уголовного процесса России / А. Б. Соловьев, М. Е. Токарева, А. Г. Халиулин, Н. А. Якубович. - Кемерово : Кузбассвузиздат, 1997. - 162 с.

12. Багмет А. М. Место и роль принципа процессуальной самостоятельности следователя в уголовном процессе / А. М. Багмет // Российская юстиция. - 2014. - № 5. - С. 20-22.

13. Гаврилов Б. Я. Правовое регулирование защиты конституционных прав и свобод участников уголовного судопроизводства : автореф. дис. ... д-ра юрид. наук : 12.00.09/ Б. Я. Гаврилов. - М., 2004. - 63 с.

14. Соловьев А. Необходимо восстановить властно-распорядительные полномочия прокурора в досудебных стадиях российского уголовного судопроизводства / А. Соловьев, М. Токарева // Уголовное право. - 2011. — № 4. - С. 98-104.

15. Турилов Г. Г. Прокурор как субъект доказывания в российском уголовном процессе : дис. ... канд. юрид. наук : 12.00 .09 / Г. Г. Турилов. - Краснодар, 2002. — 205 с.

16. Быков В. М. Права прокурора на стадии возбуждения уголовного дела / В. М. Быков // Законность. - 2013. - № 4. - С. 49-53.

17. Смирнов Г. К. Проблемы совершенствования института участия прокурора в досудебном производстве / Г. К. Смирнов // Российская юстиция. - 2008. - № 11. - С. 50-54.

18. Абдул-Кадыров Ш. М. Функции и полномочия прокурора в стадии возбуждения уголовного дела / Ш. М. Абдул-Кадыров // Законность. - 2012. — № 9. - С. 12-15.

19. Ережипалиев Д. Полномочия прокурора в стадии возбуждения уголовного дела / Д. Ережипалиев // Уголовное право. - 2011. — № 4. - С. 83-87.

20. Капинус О. С. К вопросу о процессуальном положении прокурора в стадии возбуждения уголовного дела / О. С. Капинус // Прокурор. - 2013. — № 2. - С. 50-58.

21. Корнакова С. В. О совершенствовании уголовно-процессуальных отношений на стадии возбуждения уголовного дела / С. В. Корнакова, А. В. Чубыкин // Юридическая наука и правоохранительная практика. - 2013. - № 3 (25). - С. 94-101.

22. Корнакова С. В. О полномочиях прокурора в стадии возбуждения уголовного дела в российском уголовном процессе / С. В. Корнакова, А. В. Чубыкин / Библиотека криминалиста. - 2014. - № 1 (12). - С. 110-114.

23. Моругина Н. А. Руководитель следственного органа как участник уголовного судопроизводства со стороны обвинения : автореф. дис. ... канд. юрид. наук : 12.00 .09 / Н. А. Моругина. - М., 2010. - 28 c.

24. Бурцев С. Н. Нарушения уголовно-процессуальных норм в деятельности органов дознания, средства их предупреждения и устранения : автореф. дис. ... канд. юрид. наук : 12.00 .09 / С. Н. Бурцев. - М., 2006. - 23 с.

25. Бессарабов В. Г. Защита российской прокуратурой прав и свобод человека и гражданина / В. Г. Бессарабов, К. А. Кашаев. - М. : Городец, 2007. - 464 с.

\section{References}

1. Kryukov V. F. Ugolovnoe presledovanie $v$ dosudebnom proizvodstve: ugolovno-protsessual'nye i nadzornye aspekty deyatel'nosti prokurora [Criminal prosecution in pre-trial procedure: criminal-procedural and supervision aspect of of prosecutor's activity]. Moscow, Norma Publ., 2010. $480 \mathrm{p}$.

2. Kryukov V. F. Pravovoi status prokurora v ugolovnom presledovanii: dosudebnoe $i$ sudebnoe proizvodstvo. Avtoref. Dokt. Diss. [Prosecutor's legal status in criminal prosecution: pre-trial and trial procedure. Doct. Diss. Thesis]. Moscow, 2012. $51 \mathrm{p}$.

3. Novikov E. A. Rukovoditel' sledstvennogo organa v rossiiskom ugolovnom sudoproizvodstve: protsessual'nye i organizatsionnye aspekty. Kand. Diss. [Investigative body head in Russian criminal procedure: procedural and organizational aspects. Cand. Diss.]. Moscow, 2009. 271 p.

4. Terekhin A. A. Akty prokurorskogo reagirovaniya v rossiiskom ugolovnom sudoproizvodstve. Avtoref. Kand. Diss. [Acts of prosecutor's response in Russian criminal procedure. Cand. Diss. Thesis]. Chelyabinsk, 2013. 19 p.

5. Maslov I. V. Prosecutor's supervision and departmental control in criminal procedure of Russia: functions, analysis of systemic ties. Rossiiskii sledovatel'= Russian Investigator, 2013, no. 19, pp. 27-32. (In Russian).

\section{Baikal Research Journal}


6. Morugina N. A. Rukovoditel' sledstvennogo organa kak uchastnik ugolovnogo sudoproizvodstva so storony obvineniya. Kand. Diss. [Investigative body head as a participant of criminal procedure on the part of prosecution. Cand. Diss.]. Moscow, 2010. $221 \mathrm{p}$.

7. Shabunin V. A. Rukovoditel' sledstvennogo organa: normativnoe regulirovanie i praktika osushchestvleniya protsessual'nykh funktsii i polnomochii. Avtoref. Kand. Diss. [Investigative body head: normative regulation and practice of performing procedural functions and powers. Cand. Diss. Thesis]. Saratov, 2013. 42 p.

8. Ivanova E. V. Rukovoditel' sledstvennogo organa kak sub"ekt ugolovnogo sudoproizvodstva. Avtoref. Kand. Diss. [Investigative body head as a subject of criminal procedure. Cand. Diss. Thesis]. Ekaterinburg, 2014. 28 p.

9. Minayeva S. A. Protsessual'naya deyatel'nost' rukovoditelya sledstvennogo organa po obespecheniyu zakonnosti $v$ dosudebnom proizvodstve. Avtoref. Kand. Diss. [Procedural activity of investigative body head on providing legitimacy in pre-trial procedure. Cand. Diss. Thesis]. Moscow, 2014. $26 \mathrm{p}$.

10. Popova T. Yu. Ugolovno-protsessual'nyi status rukovoditelya sledstvennogo organa. Avtoref. Kand. Diss. [Criminal-procedural status of head of investigative body. Cand. Diss. Thesis]. Chelyabinsk, 2012. $30 \mathrm{p}$.

11. Solovyev A. B., Tokareva M. E., Khaliulin A. G., Yakubovich N. A. Zakonnost'v dosudeb nykh stadiyakh ugolovnogo protsessa Rossii [Legitimacy in pre-trial stages of Russia's criminal procedure]. Kemerovo, Kuzbassvuzizdat Publ., 1997. 162 p.

12. Bagmet A. M. The place and role of the principle of procedural autonomy of the investigator in the criminal process. Rossiiskaya yustitsiya = Russian Justice, 2014, no. 5, pp. 20-22. (In Russian).

13. Gavrilov B. Ya. Pravovoe regulirovanie zashchity konstitutsionnykh prav i svobod uchastnikov ugolovnogo sudoproizvodstva. Avtoref. Kand. Diss. [Legal regulation of defending constitutional rights and freedoms of participants of criminal procedures. Cand. Diss. Thesis]. Moscow, 2004. $63 \mathrm{p}$.

14. Solovyev A., Tokareva M. Authoritative and administrative powers of prosecutors in pre-trial criminal proceedings in Russia to be restored. Ugolovnoe pravo = Criminal Law, 2011, no. 4, pp. 98-104. (In Russian).

15. Turilov G. G. Prokuror kak sub"ekt dokazyvaniya v rossiiskom ugolovnom protsesse. Kand. Diss. [Prosecutor as a subject of evidence in Russian criminal procedure. Cand. Diss.]. Krasnodar, 2002. 205 p.

16. Bykov V. M. The rights of a public prosecutor at the stage of initiation of a criminal case. Zakonnost' = Legality, 2013, no. 4, pp. 49-53. (In Russian).

17. Smirnov G. K. Problems of improving the institution of prosecutor's participation in pre-trial procedure. Rossiiskaya yustitsiya $=$ Russian Justice, 2008, no. 11, pp. 50-54. (In Russian).

18. Abdul-Kadyrov Sh. M. The duties and powers of public prosecutors at the stage of initiation of a criminal case. Zakonnost' = Legality, 2012, no. 9, pp. 12-15. (In Russian).

19. Erezhipaliyev D. Powers of the public prosecutor at the stage of excitation of criminal case. Ugolovnoe pravo = Criminal Law, 2011, no. 4, pp. 83-87. (In Russian).

20. Kapinus O. S. On issue of prosecutor's procedural status at the stage of initiating a criminal case. Prokuror = Procurator, 2013, no. 2, pp. 50-58. (In Russian).

21. Kornakova S. V., Chubykin A. V. On improving criminal and procedural relations at the stage of initiation of a criminal procedure. Yuridicheskaya nauka i pravookhranitel'naya praktika = Legal Science and Law Enforcement Practice, 2013, no. 3 (25), pp. 94-101. (In Russian).

22. Kornakova S. V., Chubykin A. V. Prosecutor's Powers at the Stage of Initiation of a Criminal Case in the Criminal Process in Russia. Biblioteka kriminalista $=$ Criminalist's Library, 2014, no. 1 (12), pp. 110-114. (In Russian).

23. Morugina N. A. Rukovoditel' sledstvennogo organa kak uchastnik ugolovnogo sudoproizvodstva so storony obvineniya. Avtoref. Kand. Diss. [Head of investigative body as a participant of criminal procedure on the part of prosecution. Cand. Diss. Thesis]. Moscow, 2010. $28 \mathrm{p}$.

24. Burtsev S. N. Narusheniya ugolovno-protsessual'nykh norm $v$ deyatel'nosti organov doznaniya, sredstva ikh preduprezhdeniya i ustraneniya. Avtoref. Kand. Diss. [Violations of criminal and procedural standards in investigating authority's activities, means of their prevention and elimination. Cand. Diss. Thesis]. Moscow, 2006. 23 p.

\section{Baikal Research Journal}


25. Bessarabov V. G., Kashayev K. A. Zashchita rossiiskoi prokuraturoi prav i svobod cheloveka $i$ grazhdanina [Defense of rights and freedoms of man and citizen by Russian prosecution service]. Moscow, Gorodets Publ., 2007. 464 p.

\section{Информация об авторе}

Ислалова Эльнара Рафисовна - кандидат юридических наук, доцент, кафедра прокурорского надзора и участия прокурора в рассмотрении уголовных гражданских и арбитражных дел, Санкт-Петербургский юридический институт (филиал) Академии Генеральной прокуратуры Российской Федерации, советник юстиции, 191104, г. Санкт-Петербург, Литейный просп., 44, e-mail: alnara@yandex.ru.

\section{Author}

Elnara R. Islamova - Ph.D. in Law, Associate Professor, Chair of Prosecutor's Supervision and Prosecutor's Participation in Hearing Criminal Civil and Arbitral Cases, Saint-Petersburg Law Institute (branch) of Academy of Prosecutor's Office, of the Russian Federation, Counsellor in Justice, 44 Liteyny Avenue, 191104, Saint-Petersburg, Russian Federation; e-mail: alnara@yandex.ru.

\section{Библиографическое описание статьи}

Исламова Э. Р. К вопросу о соотношении процессуальных полномочий прокурора и руководителя следственного органа / Э. Р. Исламова // Baikal Research Journal. — 2016. - T. 7, № 2. - DOI : 10.17150/2411-6262.2016.7(2).22.

\section{Reference to article}

Islamova E. R. On issue of correlation of prosecutor's procedural powers and head of investigative body. Baikal Research Journal, 2016, vol. 7, no. 2. DOI: 10.17150/2411-6262.2016.7(2).22. (In Russian).

\section{Baikal Research Journal}

